\title{
ANALISIS CAPACITY REQUIREMENT PLANNING PADA MESIN ROBOTIC FIBER LASER DI PT. KIYOKUNI INDONESIA
}

\author{
Achmad Yusuf Ruswantoro ${ }^{1}$, Dene Herwanto ${ }^{2}$ \\ Program Studi Teknik Industri, Universitas Singaperbangsa Karawang 1,2 \\ achmad.yusuf17020@student.unsika.ac.id ${ }^{1}$
}

Submitted February 2, 2021; Revised May 9, 2021; Accepted May 10, 2021

\begin{abstract}
Abstrak
Ketidaktepatan dalam membuat rencana kebutuhan kapasitas akan menyebabkan perusahaan mengalami kerugian. Kerugian tersebut seperti terhabatnya proses produksi akibat tidak memperhitungkan jumlah tenaga kerja dan mesin yang dibutuhkan untuk menyelesaikan kegiatan produksi. Penelitian ini bertujuan untuk mengetahui kapasitas yang dimiliki serta beban produksi yang diterima oleh mesin yang terdapat pada PT. Kiyokui Indonesia khususnya mesin Robotic Fiber Laser dengan menggunakan metode Capacity Requirement Planning yang berfungsi untuk menampilkan perbandingan antara beban yang diresmikan pada pusat- pusat kerja lewat pesanan kerja yang terdapat serta kapasitas dari tiap pusat kerja sepanjang periode waktu tertentu. PT. Kiyokuni Indonesia merupakan perusahaan yang bergerak dibidang produksi part printer yang dihasilkan dari proses stamping press dan dibantu oleh Robotic Fiber Laser dalam melakukan assembly. Dengan permintaan customer yang sangat tinggi menuntut mesin Robotic Fiber Laser memiliki beban kerja hampir 24 jam, dengan menggunakan metode Capacity Requirement Planning diketahui bahwa pada bulan Januari dan Februari mesin Robotic Fiber Laser mengalami overload, dimana kebutuhan kapasitas pada bulan Januari 58.673 menit dan pada bulan Februari 38.891 menit, lalu ketersediaan kapasitas yang dimiliki pada bulan Januari dan Februari hanya 34.500 menit tidak dapat dipenuhi kebutuhan kapasitas yang seharusnya.
\end{abstract}

Kata Kunci : Kapasitas, Beban, Capacity Requirement Planning

\begin{abstract}
Inaccuracy in planning capacity requirements will cause the company to suffer losses. Such losses include disruption in the production process due to not taking into account the number of workers and machines needed to complete production activities. This study aims to determine the capacity that is owned and the production load received by the machines contained in PT. Kiyokui Indonesia, especially the Robotic Fiber Laser machine, uses the Capacity Requirement Planning method which functions to display the comparison between the load that is inaugurated at work centers through existing work orders and the capacity of each work center during a certain period of time. PT. Kiyokuni Indonesia is a company engaged in the production of printer parts that are produced from the stamping press and assisted by the Robotic Fiber Laser in performing assemblies. With very high customer demand demanding that the Robotic Fiber Laser machine has a workload of almost 24 hours, using the Capacity Requirement Planning method, it is known that in January and February the Robotic Fiber Laser machine has overloaded, where the capacity requirement is 58,673 minutes in January and in February. 38,891 minutes, then the available capacity in January and February was only 34,500 minutes which could not be fulfilled the capacity needs that it should have.
\end{abstract}

Key Words : Capacity, Load, Capacity Requirement Planning

\section{PENDAHULUAN}

Ketidaktepatan dalam membuat rencana kebutuhan kapasitas hendak menimbulkan industri hadapi kerugian. Kerugian tersebut semacam terhambatnya proses penciptaan akibat tidak memperhitungkan jumlah tenaga kerja serta mesin yang diperlukan 
buat menuntaskan aktivitas penciptaan. Hingga dari itu, diperlukan sesuatu pendekatan yang dapat menolong industri dalam merancang kebutuhan kapasitas penciptaan.

Ada pula pendekatan yang dapat dicoba merupakan dengan memakai Capacity Requierment Planning (CRP). CRP merupakan guna buat memastikan, mengukur, serta membiasakan tingkatan kapasitas ataupun proses buat memastikan jumlah tenaga kerja serta sumber energi mesin yang dibutuhkan buat melakukan penciptaan. [1]

PT. Kiyokuni Indonesia adalah perusahaan yang bergerak dibidang produksi part yang dihasilkan dari proses stamping yang menggunakan dies sebagai untuk pembuatan suatu produk. Selain bergerak dibidang produksi part, perusahaan ini juga bergerak dibidang pembuatan dies, perawatan dies dan jasa seperti assembly.

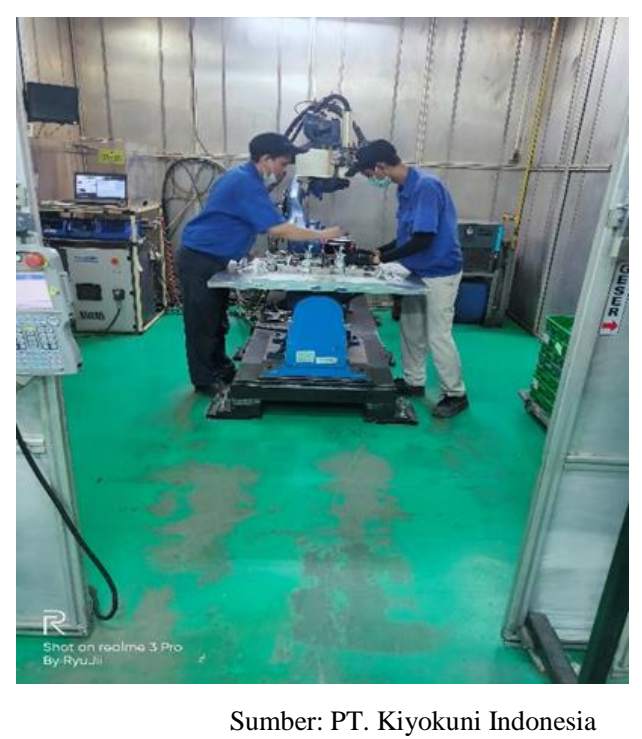

Gambar 1. Cabine Mesin Robotic Fiber Laser

Pada PT. Kiyokuni terdapat robotic yang digunakan sebagai alat bantu untuk proses assembly, robotic yang dimaksud adalah Robotic Fiber Laser. Cara kerja Robotic ini adalah mengelas part sesuai program yang telah dibuat, Dengan permintaan customer yang sangat tinggi ini menuntut mesin
Robotic Fiber Laser memiliki beban kerja hampir 24 jam perhari, ini menuntu para pekerja (operator) harus bekerja overtime tiap harinya begitupun dengan jam operasi yang diterima oleh mesin Robotic Fiber Laser.

\section{Tabel 1. Data Part yang Dikerjakan Robotic} Fiber Laser

\begin{tabular}{|c|c|c|c|}
\hline No & Model & Nomor Part & Nama Part \\
\hline 1 & GAGA 1 & $1668208-03$ & FRAME ASSY, MAIN CASSETTE,FR \\
\hline 2 & GAGA 1 & $1688223-02$ & FRAME ASSY, SCANNER, FR \\
\hline 3 & GAGA 1 & 1689295-06 & FRAME ASSY, MAIN LU \\
\hline 4 & GAGA 1 & $1688620-03$ & FLAP ASSY, FU,MU, UPPER EJ \\
\hline 5 & GAGA 1 & $1688624-00$ & FLAP ASSY, FU, FD, UPPER EJ \\
\hline 6 & GAGA 1 & 1688709-01 & FLAP, DUP, ASSY, EJ \\
\hline 7 & GAGA MU & 1611947-02 & FRAME BASE, ASSY, MU \\
\hline 8 & GAGAMU & 1711968-01 & FLAP ASSY, DIVEGENT, UPPER, MU \\
\hline 9 & GAGA MU & 1711975-01 & FLAP ASSY, RIGHT, UPPER, MU \\
\hline 10 & GAGA 2 & 1799918-00 & FRAME ASSY, CASSETTE, FR \\
\hline 11 & GAGA 2 & 1798384-00 & FRAME ASSY SCANNER, FR \\
\hline 12 & GAGA 2 & 1799983-00 & FRAME ASSY, MAIN LU \\
\hline 13 & GAGA 2 & 1799937-00 & PLATE ASSY BASE, HM \\
\hline 14 & GAGA 2 MU & 1809304-00 & PAPER GUIDE ASSY RIGHT \\
\hline 15 & GAGA 2 MU & 1809305-00 & FLAP ASSY DIVERGENT UPPER MU 2 \\
\hline 16 & GAGA 2 MU & 1809306-00 & PG ASSY MOVABLEMU2 \\
\hline 17 & GAGA 2 MU & 1809307-00 & PG ASSY LEFT MOVABLEMU 2 \\
\hline 18 & GAGA 2 MU & 1809284-00 & FRAME BASE ASSY MU 2 \\
\hline 19 & GAGA FINISHER & $1812273-00$ & STAY ASSY RIGHT UPPER FI \\
\hline 20 & GAGA FINISHER & 1812284-00 & FRAME ASSY FRONT UPPER FI \\
\hline 21 & GAGA FINISHER & 1814928-00 & LEVER ASSY FLAP 1ST FI \\
\hline 22 & GAGA FINISHER & $1818322-00$ & FRAME ASSY LEFT UPPER FI \\
\hline
\end{tabular}

Namun walaupun sudah diberikan beban kerja selama hampir 24 jam kerja untuk Robotic Fiber Laser, ini masih belum dapat memenuhi kebutuhan kapasitas yang diminta oleh customer.

Standarisasi merupakan proses penentuan spesifikasi sesuatu produk ataupun (dimensi, wujud, ciri, yang lain). Pada CRP yang terdapat pada PT. Kiyokuni Indonesia mempunyai standar yang wajib dipadati supaya jadi perataan beban kerja pada mesin Robotic Fiber Laser. 


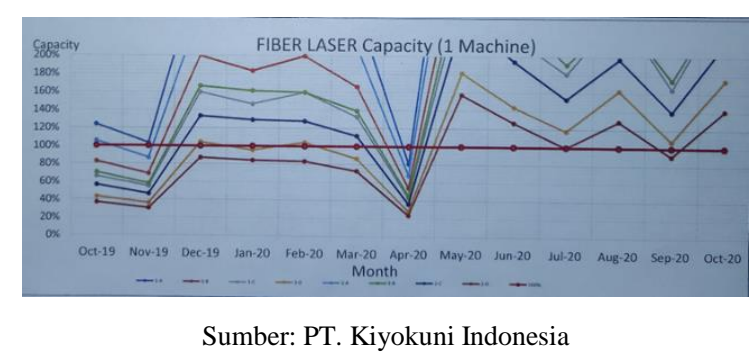

Gambar 2. Standart CRP Robotic Fiber Laser

Dari gambar diatas adalah grafik yang menunjukan hasil CRP yang telah dihitung, dan diketahui standar yang dimiliki adalah $100 \%$ atau kapasitas tersedia sama dengan kebutuhan kapasitas (Kapasitas tersedia $=$ Kebutuhan kapasitas). Namun lebih baik kapasitas tersedia lebih banyak dari kebutuhan kapasitas, karena sisa dari part atau produk yang ada bisa dijadikan safety stock apabalia terjadi keadaan yang tidak diinginkan

Dengan permasalahan yang terjadi pada perusahaan tersebut maka harus dilakukan perencanaan kapasitas produksi kembali. Tujuan dari penelitian ini mengtahui perbandingan kapasitas dan beban yang dimiliki oleh mesin Robotic Fiber Laser apakah overload atau underload, sekaligus menjadi pertimbangan untuk melakukan perencanaan kapasitas produksi untuk kedepannya.

Kapasitas merupakan sesuatu tingkatan keluaran sesuatu kuantitas keluaran dalam periode tertentu serta ialah kuantitas keluaran paling tinggi yang bisa jadi sepanjang periode waktu itu. [2]. Menurut Handoko jenis kapasitas dapat dibagi atas; design capacity, rated capacity, standart capacity, actual / operation capacity, peak capacity.

Beban (load) merupakan banyaknya kerja yang dijadwalkan buat dicoba oleh sarana manufacturing dalam periode waktu yang sudah diresmikan. Beban (load) biasa dinyatakan dalam dimensi jam kerja ataupun unit penciptaan. Beban ialah volume kerja yang dikerjakan. Beban (load) menggambarkan waktu setup (setup time) serta waktu penerapan yang diperlukan dari sesuatu pusat kerja, tidak tercantum waktu menunggu, waktu antri serta waktu bergerak. [1]

Tujuan utama CRP merupakan menampilkan perbandingan antara beban yang diresmikan pada pusat- pusat kerja lewat pesanan kerja yang terdapat serta kapasitas dari tiap pusat kerja sepanjang periode waktu tertentu. Lewat identifikasi overloads ataupun underloads, bila terdapat, aksi perencanaan kembali (replanning) bisa dicoba buat melenyapkan suasana itu guna menggapai sesuatu penyeimbang antara beban serta kapasitas (balanced load). Bila arus kehadiran pesanan melebihi kapasitas, beban hendak bertambah, yang diisyarati oleh inventory yang terletak dalam antrian kerja yang tidak diproses di depan pusat kerja. Kebalikannya bila arus kehadiran pesanan lebih sedikit daripada kapasitas yang terdapat, beban (pesanan yang menunggu buat diproses) hendak menurun. [3]

Tujuan dari perencanaan kapasitas pada tingkat ketiga dari hierarki perencanaan kapasitas merupakan berupaya mengendalikan secara bersama- sama pesanan kerja yang tiba serta/ ataupun kapasitas dari pusat kerja buat menggapai sesuatu aliran yang mantap ataupun balance. Apabila beban meningkat, yang diisyarati oleh banyaknya antrian, hingga waktu tunggu pusat kerja (work center lead time) hendak lebih panjang. Penindakan ikatan antara kapasitas serta beban didasarkan pada keahlian sistem perencanaan serta penerapan buat membiasakan tingkatan kehadiran pesanan serta kapasitas. Unit pengukuran dari beban serta kapasitas paling banyak memakai jam kerja selam interval waktu tertentu. [4]

CRP membolehkan untuk menyeimbangkan beban (load) terhadap 
kapasitas (capacity). Tindakan- tindakan ini bisa dicoba secara sendiri ataupun dalam bermacam wujud campuran yang disesuaikan dengan suasana serta keadaan aktual dari industri industri manufaktur tersebut. 5 aksi dasar bagi Gaspersz yang bisa jadi diambil apabila terjalin perbandingan (ketidakseimbangan) antara kapasitas yang terdapat dengan beban yang diperlukan ialah; tingkatkan kapasitas, kurangi beban, merendahkan kapasitas, menaikan beban, mendistribusikan kembali beban. [5]

\section{METODE PENELITIAN}

Penelitian ini dilakukan dengan cara mengamati langsung kejadian atau proses yang terjadi, pengamatan dilakukan selama 1 bulan mulai dari tanggal 20 Januari 2020 hingga 20 Februari 2020 pada PT. Kiyokuni Indonesia pada bagian Production Press Divisi Fiber Laser.

Data yang digunakan dalam perhitungan CRP merupakan data sekunder yaitu data yang diperoleh secara tidak langsung namun masih relevan dan terkait dengan topik masalah pada penelitian ini. Datadata yang diperlukan dalam penelitian ini berupa data forecasting model GAGA, cycle time tiap proses, hari kerja dan jam kerja. [6]

Adapun alur dalam menentukan CRP (Capcity Requirement Planning) dan cara perhitungan maupun rumus yang digunakan adalah sebagai berikut: [7]

a. Penentuan Peramalan (Forcasting)

Penentuan forcasting didapat dari hasil perhitungan berdasarkan permintaan dari tahun-tahun sebelumnya.

b. Penentuan Cycle Time

Penentuan cycle time pada PT. Kiyokuni Indonesia dengan cara melakukan trial running process beberapa kali dan mencari rata-rata dari trial running process tersebut yang digunakan sebagai acuan untuk mentukan kapasitas produksi.

c. Menghitung Kapasitas Produksi

Perhitungan kapasitas produksi dipengaruhi oleh jam dan hari kerja operator yang mengoperasikan mesin Robotic Fiber Laser. PT. Kiyokuni Indonesia mengklasifikasikan kedalam 8 kategori.

d. Menghitung Beban Kerja

Perhitungan beban kerja didapat dari perkalian antara cycle time dan forecasting.

e. Menghitung CRP (Capacity

Requirement Planning)

Perhitungan CRP dilakukan untuk mengetahui jumlah kapasitas dimiliki, beban kerja yang didapat, serta perbandingan antara beban kerja dan kapasitas produksi.

Selain melakukan pengamatan dilakukan juga wawancara secara non formal kepada karyawan atau operator yang bekerja pada mesin Robotic Fiber Laser, untuk mendapatkan data forecasting, cycle time, schedule receipt, kemudian data tersebut diolah dengan menggunakan metode Capacity Requirement Planning (CRP). CRP adalah proses penentuan jumlah tenaga kerja dan mesin yang dibutuhkan untuk menyelesaikan kegiatan produksi, data yang digunakan adalah data sekunder yang didapat dari perusahaan.

\section{HASIL DAN PEMBAHASAN}

Pada pengumpulan data dari ketetapan perusahaan yaitu forecasting yang berguna untuk peramalan target jumlah produsi. Forecasting merupakan sesuatu aktivitas ataupun usaha buat mengenali peristiwaperistiwa ataupun events yang hendak terjalin pada waktu yang hendak tiba. Sesuai data yang diperoleh dari PT. Kiyokuni Indonesia, data forecasting yang diperoleh adalah data forecasting pada bulan Januari dan Februari. 
Tabel 2. Data Forecasting Model GAGA

\begin{tabular}{clccc}
\hline \multirow{2}{*}{ No } & \multirow{2}{*}{ Model } & Category & \multicolumn{2}{c}{ Forcasting } \\
& & & January & February \\
\hline 1 & GAGA 1 & Mecha & 595 & 252 \\
2 & GAGA 2 & Mecha & 1329 & 1002 \\
3 & GAGA MU & Option & 54 & 73 \\
4 & GAGA 2 MU & Option & 703 & 127 \\
5 & GAGA FINISHER & Option & 200 & 200 \\
\hline
\end{tabular}

Sumber: PT. Kiyokuni Indonesia

Dari diatas merupakan hasil forecasting, dimana terdapat 5 model yang harus dipenuhi kebutuhannya oleh perusahaan. Dalam satu model terdapat 4 hingga 5 part yang harus dibuat.

Kapasitas Tersedia ialah output penciptaan ataupun jumlah unit yang ditahan, ditaruh, diterima, ataupun dibuat oleh suatu mesin dalam satu periode tertentu. Sesuai dengan data yang diperoleh dari PT. Kiyokuni Indonesia mesin Robotic Fiber Laser dalam 1 (satu) bulan rata-rata terdapat 22 hari kerja dan 23 jam kerja dalam sehari. Perhitngan kapasitas tersedia dilakukan dengan persamaan berikut:

Kapasitas $=$

Jumlah hari kerja $x$ jam kerja $x 60$

Tabel 3. Data Kapasitas Tersedia mesin Robotic Fiber Laser bulan Januari dan Februari

\begin{tabular}{|c|c|c|c|c|c|}
\hline \multirow{2}{*}{ Klasifikasi- } & \multicolumn{2}{|c|}{ Jumlah Hari Kerja (Hari) } & \multirow{2}{*}{$\begin{array}{c}\text { Jam Kerja } \\
(\mathrm{Jam})\end{array}$} & \multicolumn{2}{|c|}{ Kapasitas Tersedia (Menit) } \\
\hline & Januari & Februari & & Januari & Februari \\
\hline $1-\mathrm{A}$ & 22 & 20 & 8 & 10560 & 9600 \\
\hline $1-B$ & 22 & 20 & 12 & 15840 & 14400 \\
\hline $1-\mathrm{C}$ & 22 & 20 & 15 & 19800 & 18000 \\
\hline $1-\mathrm{D}$ & 22 & 20 & 23 & 30360 & 27600 \\
\hline 2-A & 25 & 25 & 8 & 12000 & 12000 \\
\hline $2-B$ & 25 & 25 & 12 & 18000 & 18000 \\
\hline $2-\mathrm{C}$ & 25 & 25 & 15 & 22500 & 22500 \\
\hline 2-D & 25 & 25 & 23 & 34500 & 34500 \\
\hline
\end{tabular}

Sumber: Pengolahan Data

Dari tabel diatas, maka diketahui hasil perhitungan kapasitas tersedia dari bulan Januari dan Februari, Adapun klasifikasi yang dibuat yaitu:
a. 1-A: Normal Day One Shift
b. 1-B: Normal Day One Shift + Overtime

c. 1-C: Normal Day 2 Shift

d. 1-D: Normal Day 2 Shift + Overtime

e. 2-A: With Saturday One Shift

f. 2-B: With Saturday One Shift+Overtime

g. 2-C: With Saturday 2 Shitf

h. 2-D: With Saturday 2 Shift + Overtime

Cycle time ialah waktu yang digunakan buat menuntaskan penciptaan satu unit ataupun proses dari dini sampai akhir

Tabel 4. Cycle Time Tiap Part

\begin{tabular}{|c|c|c|c|c|c|c|}
\hline No & Model & Nomor Part & Nama Part & Cavity & $\begin{array}{l}\text { Cycle Time } \\
\text { (Menit) }\end{array}$ & $\begin{array}{l}\text { Cycle Time/Unit } \\
\text { (Menit) }\end{array}$ \\
\hline 1 & GAGA 1 & $1668208-03$ & FRAME ASSY, MAIN CASSETTE,FR & 1 & 11.05 & 11.05 \\
\hline 2 & GAGA 1 & $1688223-02$ & FRAME ASSY, SCANNER, FR & 1 & 2.15 & 2.15 \\
\hline 3 & GAGA 1 & $1689295-06$ & FRAME ASSY, MAIN LU & 1 & 6.48 & 6.48 \\
\hline 4 & GAGA I & $1688620-03$ & FLAP ASSY,FU,MU,UPPER EJ & 3 & 2.46 & 0.82 \\
\hline 5 & GAGA 1 & 168862400 & FLAP ASSY,FU,FD, UPPER EJ & 3 & 1.38 & 0.46 \\
\hline 6 & GAGA 1 & 1688709-01 & FLAP, DUP, ASSY, EJ & 2 & 1.20 & 0.60 \\
\hline 7 & GAGA MU & 1611947-02 & FRAME BASE, ASSY,MU & 1 & 1.22 & 1.22 \\
\hline 8 & GAGA MU & $1711968-01$ & FLAP ASSY, DIVEGENT,UPPER, MU & 2 & 2.47 & 1.23 \\
\hline 9 & GAGA MU & $1711975-01$ & FLAP ASSY, RIGHT, UPPER, MU & 3 & 1.16 & 0.39 \\
\hline 10 & GAGA 2 & $1799918-00$ & FRAME ASSY,CASSETTE, FR & 1 & 1.53 & 1.53 \\
\hline 11 & GAGA 2 & 1798384-00 & FRAME ASSY SCANNER, FR & 1 & 2.63 & 2.63 \\
\hline 12 & GAGA 2 & 17999983-00 & FRAME ASSY, MAIN LU & 1 & 8.57 & 8.57 \\
\hline 13 & GAGA 2 & 1799937-00 & PLATE ASSY BASE, HM & 1 & 1.85 & 1.85 \\
\hline 14 & GAGA 2MU & 180930400 & PAPER GUIDE ASSY RIGHT & 1 & 0.84 & 0.84 \\
\hline 15 & GAGA $2 \mathrm{MU}$ & $1809305-00$ & FLAP ASSY DIVERGENT UPPER MU 2 & 1 & 1.26 & 1.26 \\
\hline 16 & GAGA $2 \mathrm{MU}$ & $1809306-00$ & PG ASSY MOVABLE MU 2 & 1 & 1.85 & 1.85 \\
\hline 17 & GAGA 2MU & $1809307-00$ & PG ASSY LEFT MOVABLE MU 2 & 1 & 4.56 & 4.56 \\
\hline 18 & GAGA 2MU & 180928400 & FRAME BASE ASSY MU 2 & 1 & 7.02 & 7.02 \\
\hline 19 & GAGA FINISHER & $1812273-00$ & STAY ASSY RIGHT UPPER FI & 2 & 3.57 & 1.78 \\
\hline 20 & GAGA FINISHER & 181228400 & FRAME ASSY FRONT UPPER FI & 1 & 0.85 & 0.85 \\
\hline 21 & GAGA FINISHER & $1814928-00$ & LEVER ASSY FLAP IST FI & 2 & 0.27 & 0.14 \\
\hline 22 & GAGA FINISHER & $1818322-00$ & FRAME ASSY LEFT UPPER FI & 1 & 0.58 & 0.58 \\
\hline
\end{tabular}

Kebutuhan Kapasitas atau beban kerja yang harus dapat dipenuhi oleh mesin Robotic Fiber Laser. Beban ialah banyaknya kerja yang dijadwalkan buat dicoba oleh sarana manufacturing dalam periode waktu yang sudah diresmikan. Beban (load) biasa dinyatakan dalam dimensi jam kerja ataupun unit produksi. Perhitungan kebutuhan kapasitas (load) yang dilakukan dengan persamaan:

Load $=$ Cycle time $x$ Forecasting 
Tabel 5. Kebutuhan Kapasitas GAGA 1

\begin{tabular}{|c|c|c|c|c|c|c|c|}
\hline \multirow[b]{2}{*}{ No } & \multirow[b]{2}{*}{ Model } & \multirow[b]{2}{*}{ Nomor Part } & \multirow[b]{2}{*}{ Nama Part } & \multirow{2}{*}{ Category } & \multirow{2}{*}{$\begin{array}{c}\text { Cycle } \\
\text { Time/Unit } \\
\text { (Menit) }\end{array}$} & \multicolumn{2}{|c|}{ Beban Kerja (Menit) } \\
\hline & & & & & & $\begin{array}{c}\text { Januari } \\
595\end{array}$ & $\begin{array}{c}\text { Februari } \\
252\end{array}$ \\
\hline 1 & GAGA I & $1668208-03$ & FRAME ASSY, MAIN CASSETTE,FR & Mecha & 11.05 & 6575 & 2785 \\
\hline 2 & GAGA 1 & $1688223-02$ & FRAME ASSY, SCANNER, FR & Mecha & 2.15 & 1279 & 542 \\
\hline 3 & GAGA 1 & $1689295-06$ & FRAME ASSY,MAIN LU & Mecha & 6.48 & 3858 & 1634 \\
\hline 4 & GAGA 1 & $1688620-03$ & FLAP ASSY,FU,MU,UPPER EJ & Mecha & 0.82 & 274 & 116 \\
\hline 5 & GAGA 1 & 1688624.00 & FLAP ASSY,FU,FD, UPPER EJ & Mecha & 0.46 & 238 & 101 \\
\hline 6 & GAGA 1 & $1688709-01$ & FLAP,DUP, ASSY, EJ & Mecha & 0.60 & 361 & 153 \\
\hline
\end{tabular}

Tabel 6. Kebutuhan Kapasitas GAGA 2

\begin{tabular}{|c|c|c|c|c|c|c|c|}
\hline \multirow[b]{2}{*}{$\mathrm{N}_{0}$} & \multirow[b]{2}{*}{ Model } & \multirow[b]{2}{*}{ Nomor Part } & \multirow[b]{2}{*}{ Nama Part } & \multirow{2}{*}{ Category } & \multirow{2}{*}{$\begin{array}{c}\text { Cycle } \\
\text { Time/Unit } \\
\text { (Menit) }\end{array}$} & \multicolumn{2}{|c|}{ Beban Kerja } \\
\hline & & & & & & $\begin{array}{c}\text { Januari } \\
1329\end{array}$ & $\begin{array}{c}\text { Februari } \\
1002\end{array}$ \\
\hline 1 & GAGA2 & 1799918-00 F & Y,CASSETTE, FR & Mecha & 1.53 & 14883 & 11221 \\
\hline 2 & GAGA2 & $179838400 \mathrm{~F}$ & Y SCANNER,FR & Mecha & 2.63 & 2452 & 1849 \\
\hline 3 & GAGA2 & 1799983-00 F & Y,MAIN LU & Mecha & 8.57 & 20650 & 15569 \\
\hline 4 & GAGA2 & 1799937-00 P & Y BASE, HM & Mecha & 1.85 & 4738 & 3572 \\
\hline
\end{tabular}

Sumber: Pengolahan Data

Tabel 7. Kebutuhan Kapasitas GAGA MU

\begin{tabular}{|c|c|c|c|c|c|c|c|}
\hline \multirow[b]{2}{*}{$\mathrm{N}_{0}$} & \multirow[b]{2}{*}{ Model } & \multirow[b]{2}{*}{ Nomor Part } & \multirow[b]{2}{*}{ Nama Part } & \multirow[b]{2}{*}{ Category } & \multirow[b]{2}{*}{$\begin{array}{l}\text { Cycle } \\
\text { Time//nit } \\
\text { (Menit) }\end{array}$} & \multicolumn{2}{|c|}{ Beban Kerja } \\
\hline & & & & & & $\begin{array}{c}\text { Januari } \\
54 \\
\end{array}$ & $\begin{array}{c}\text { Februari } \\
73\end{array}$ \\
\hline 1 & GAGA MU & $1611947-02$ & FRAME BASE, ASSY,MU & Option & 1.22 & 133 & 180 \\
\hline 2 & GAGA MU & $1711968-01$ & FLAP ASSY, DIVEGENT, UPPER, MU & Option & 1.23 & 31 & 42 \\
\hline 3 & GAGA MU & $1711975-01$ & FLAP ASSY, RIGHT, UPPER, MU & Option & 0.39 & 28 & 37 \\
\hline
\end{tabular}
Sumber: Pengolahan Data

Tabel 8. Kebutuhan Kapasitas GAGA 2 MU

\begin{tabular}{|c|c|c|c|c|c|c|c|}
\hline \multirow[b]{2}{*}{$\mathrm{N}_{0}$} & \multirow[b]{2}{*}{ Model } & \multirow[b]{2}{*}{ Nomor Part } & \multirow[b]{2}{*}{ Nama Part } & \multirow{2}{*}{ Category } & \multirow{2}{*}{$\begin{array}{c}\text { Cycle } \\
\text { yime//nit } \\
\text { (Menit) } \\
\end{array}$} & \multicolumn{2}{|c|}{ Beban Kerja } \\
\hline & & & & & & $\begin{array}{c}\text { Januari } \\
703\end{array}$ & $\begin{array}{c}\text { Februari } \\
127\end{array}$ \\
\hline 1 & GAGA 2MU & $1809304-00$ & GUIDE ASSY RIGHT & Option & 0.84 & 599 & 108 \\
\hline 2 & GAGA $2 \mathrm{MU}$ & $1809305-00$ & SSY DIVERGENT UPPER MU 2 & Option & 1.26 & 190 & 34 \\
\hline 3 & GAGA $2 \mathrm{MU}$ & $18030306-00$ & Y MOVABLE MU 2 & Option & 1.85 & 406 & 73 \\
\hline 4 & GAGA 2MU & $18030307-00$ & Y LEFT MOVABLE MU 2 & Option & 4.56 & 294 & 53 \\
\hline 5 & GAGA2MU & $180284+00$ & BASEASSY MU 2 & Option & 7.02 & 1010 & 182 \\
\hline
\end{tabular}
Sumber: Pengolahan Data

Tabel 9. Kebutuhan Kapasitas GAGA FINISHER

\begin{tabular}{|c|c|c|c|c|c|c|c|}
\hline \multirow[b]{2}{*}{$\mathrm{N}_{0}$} & \multirow[b]{2}{*}{ Model } & \multirow[b]{2}{*}{ Nomor Part } & \multirow[b]{2}{*}{ Nama Part } & \multirow{2}{*}{ Category } & \multirow{2}{*}{$\begin{array}{c}\text { Cycle } \\
\text { Time//nit } \\
\text { (Menit) }\end{array}$} & \multicolumn{2}{|c|}{ Beban Kerja } \\
\hline & & & & & & $\begin{array}{c}\text { Januari } \\
200\end{array}$ & $\begin{array}{c}\text { Februari } \\
200\end{array}$ \\
\hline 1 & GAGA FINSHER & $181273-00$ & STAY ASSY RIGHT UPPER FI & Option & 1.78 & 93 & 93 \\
\hline 2 & GAGA FIISHER & $181228400 \mathrm{H}$ & FRAME ASSY FRONT UPPER FI & Option & 0.85 & 84 & 84 \\
\hline 3 & GAGA FINISHER & $1814928-00 \mathrm{I}$ & LEVER ASSY FLAP IST FI & Option & 0.14 & 83 & 83 \\
\hline 4 & GAGA FINISHER & $1818322-00 \mathrm{~F}$ & FRAME ASSY LEFT UPPER FI & Option & 0.58 & 379 & 379 \\
\hline
\end{tabular}

Berdasarkan tabel 5 hingga 9 diatas merupakan hasil perhitungan kebutuhan kapasitas yang harus dipenuhi mesin Robotic Fiber Laser, tiap model memiliki forecasting yang berbeda beda sehingga penentuan jumlah kebutuhan kapasitas produksi beragam.

Maka total kebutuhan kapasitas produksi yang harus dipenuhi oleh mesin Robotic Fiber Laser yaitu sesuai dengan tabel 10 berikut:

Tabel 10. Kebutuhan Kapasitas Model GAGA

\begin{tabular}{rlccr}
\hline \multirow{2}{*}{ No } & \multirow{2}{*}{ Model } & Category & $\begin{array}{c}\text { Kebutuhan Kapasitas } \\
\text { January }\end{array}$ & February \\
\hline 1 & GAGA 1 & Mecha & 12584 & 5330 \\
2 & GAGA 2 & Mecha & 42723 & 32211 \\
3 & GAGA MU & Option & 192 & 259 \\
4 & GAGA 2 MU & Option & 2498 & 451 \\
5 & GAGA FINISHER & Option & 639 & 639 \\
\hline & & TOTAL & $\mathbf{5 8 6 3 7}$ & $\mathbf{3 8 8 9 1}$. \\
& & \multicolumn{3}{c}{ Sumber: Pengolahan Data }
\end{tabular}

Berdasarkan Tabel 10, maka didapat kebutuhan kapasitas proses Robotic Fiber Laser Model GAGA.

Capacity Requirement Planning (CRP) ialah proses memastikan jumlah mesin, jumlah tenaga kerja yang dibutuhkan buat menuntaskan aktivitas penciptaan, dan CRP pula bisa memastikan beban kerja masing- masing pusat aktivitas yang didasarkan pada agenda produksi. Perhitungan Capacity Requirement Planning yang dilakukan dengan persamaan:

$C R P=\frac{\text { Beban }}{\text { Kapasitas }} \times 100 \%$

Tabel 11. Capacity Requirement Planning Mesin Robotic Fiber Laser

\begin{tabular}{crrrrrr}
\hline \multirow{2}{*}{ Klasifikasi } & \multicolumn{2}{c}{ Kapasitas Tersedia } & \multicolumn{2}{c}{ Kebutuhan Kapasitas } & \multicolumn{2}{c}{ CRP } \\
& Januari & Februari & Januari & Februari & Januari & Februari \\
\hline 1-A & 10560 & 9600 & 58637 & 38891 & $555 \%$ & $405 \%$ \\
1-B & 15840 & 14400 & 58637 & 38891 & $370 \%$ & $270 \%$ \\
1-C & 19800 & 18000 & 58637 & 38891 & $296 \%$ & $216 \%$ \\
1-D & 30360 & 27600 & 58637 & 38891 & $193 \%$ & $141 \%$ \\
2-A & 12000 & 12000 & 58637 & 38891 & $489 \%$ & $324 \%$ \\
2-B & 18000 & 18000 & 58637 & 38891 & $326 \%$ & $216 \%$ \\
2-C & 22500 & 22500 & 58637 & 38891 & $261 \%$ & $173 \%$ \\
2-D & 34500 & 34500 & 58637 & 38891 & $170 \%$ & $113 \%$ \\
\hline & & \multicolumn{5}{c}{ Sumber: Pengolahan Data }
\end{tabular}

Jadi diperoleh hasil perhitungan kapasitas produksi dengan metode Capacity Requirement Planning (CRP) yaitu terjadi 
overload atau berkelebihan kerja yang dialami mesin Robotic Fiber Laser. Diketahui Robotic Fiber Laser memiliki beban kerja pada bulan Januari sebanyak 58.637 menit dan pada bulan Februari sebanyak 38.891 menit, dimana Robotic Fiber Laser hanya memiliki kapasitas tersedia sebanyak 34.500 menit pada bulan Januari dan Februari. Ini membuat Robotic Fiber Laser memiliki persentase Capacity Requirement Planning (CRP) melebihi dari standart perusahaan yaitu $100 \%$.

\section{SIMPULAN}

Penerapan Capacity Requierment Planning pada mesin Robotic Fiber Laser di PT. Kiyokuni Indonesia sudah memenuhi seluruh kriteria dari perencanaan kebutuhan kapasitas. Namun diperoleh bahwa hasil perhitungan dengan menggunakan metode Capacity Requierment Planning bahwa pada bulan Januari dan Februari mesin Robotic Fiber Laser Mengalami Overload dengan hasil CRP pada semua klasifikasi diata $100 \%$ ini harus menjadi perhatian penting bagi perusahaan. Perusahaan harus dapat menyeimbangkan kebutuhan kapasitas dengan kapasitas tersedia agar dapat menyelesaikan kegiatan produksi sesuai dengan jadwal yang telah dibuat.

Dari analisis diatas diketahui bahwa mesin Robotic Fiber Laser tidak dapat memenuhi kebutuhan kapasitas yang diinginkan oleh customer, maka dari itu ada beberapa cara untuk menyimbangkan beban kerja yang didapat oleh mesin Robotic Fiber Laser, yaitu: Penambahan jumlah mesin; Mempercepat cycle time dari tiap part; Menambah jam kerja (over time); Subcontrac dengan perusahaan lain; dan Membatasi permintaan customer

\section{DAFTAR PUSTAKA}

[1] V. Gaspersz, Production Planning and Inventory Control, Jakarta: Gramedia Pustaka Umum, 2005.

[2] T. Handoko, Manajemen, Yogyakarta: BEFE, 1986.

[3] T. Baroto, Perencanaan dan Pengendalian Produksi, Jakarta: Ghalia Indonesia, 2002.

[4] S. Lalu, Dasar Dasar Manajemen Produksi dan Operasi, Jakarta: Salemba Empat, 2003.

[5] A. Pangestu, "Analisis Kapasitas Produksi Okky Jelly Drink dengan Metode Capacity Requirement Planning," p. 1, 2020.

[6] T. R. Nita Marikena, "Capacity Requirement Planning Produk Mainan Kereta pada PT.X," IESM, p. 1, 2019.

[7] A. W. Rika Kartika Sihotang, "Perencanaan Kapasitas Produksi Dengan Metode Capacity Requirement Planning di Teaching Factory Manufacture Electronic Politeknik Negeri Batam," Journal of business Adminitration, p. 01, 2017.

[8] Z. H. Siregar, "Penggunaan Metode Capacity Requirement Planning dengan Aplikasi POM for Windows dalam perhitungan Kapasitas Produksi," Vorteks, p. 01, 2020. 